\title{
Psychiatric morbidities of female obesity before and after dieting: an Egyptian sample
}

\author{
Amr Said Shalaby ${ }^{1}$, Sadik Abdel Maseeh Sadik ${ }^{2}$ and Dalia Abdel Moneim Mahmoud ${ }^{3^{*}}$ (D)
}

\begin{abstract}
Background: The rate of occurrence of psychiatric morbidities like anxiety, depression, perceived stress, and the overall quality of life are very high among female patients with obesity; therefore, our study investigates such variables before and after weight loss in female patients on diet restriction; this can help obesity-multidisciplinary teams target these psychiatric correlates to reach a more satisfactory outcome.

Results: Anxiety, depression, and perceived stress scores decreased significantly in parallel to the weight loss reported $(p<0.0001)$. Except for social functioning, all other domains of quality of life improved significantly after weight loss. Those with higher education level showed significantly lower stress, anxiety, and depression scores before weight loss compared to married and highly educated ones respectively. After weight loss, highly educated participants showed lower perceived stress and depression scores than those with middle education.

Conclusions: Anxiety, depression, and perceived stress factors are significantly decreased after weight reduction with an improved quality of life as well compared to their scores prior.
\end{abstract}

Keywords: Psychiatric morbidities, Obesity, Female, Dieting

\section{Background}

The World Health Organization has pointed to obesity (where the body mass index (BMI) is $30 \mathrm{~kg} / \mathrm{m}^{2}$ or more) as one of the most prevented pandemics which have negative general medical and psychosocial consequences [1]. Low and middle income countries face a multifaceted challenge caused by obesity. Egypt has reported the occurrence of obesity among $31.4 \%$ of the adolescent population [2].

The literature explains that he hypothalamic-pituitary-adrenal axis dysregulation is responsible for appetite dysregulation and subsequent weight gain in patients with stressful life event $[3,4]$ as chronic stress is known

\footnotetext{
* Correspondence: dollycage@hotmail.com

This work was conducted at Obesity Clinic at Menoufia University Hospitals, Egypt.

${ }^{3}$ Okasha Institute of Psychiatry, Neuropsychiatry Department, Faculty of Medicine, Ain Shams University, Ramsis Street, Abbassia Square, Cairo 11591, Egypt

Full list of author information is available at the end of the article
}

to contribute to an increased risk of food addiction and obesity by enhancing the role of coping with compulsive behaviors like eating through the mesolimbic dopaminergic system and other brain regions involved in stress/ motivation circuits synergistically potentiating the reward sensitivity, food preference, and craving for hyperpalatable foods [5].

Obesity is believed to be closely linked to mental health problems especially anxiety, depression [6], and stress [7]. There are other factors that contribute to contracting obesity like dire physical health, lack of physical exercise, deficient social support, low level of education, and financial burdens [8]. An Egyptian study found that $22.31 \%$ of mentally ill patients suffered from obesity, with the highest prevalence among patients with bipolar disorder (41.38\%), (37.93\%) among patients with depression, schizophrenia (10.34\%), anxiety disorder (6.9\%), and substance abuse disorder (3.45\%) [9]. Another systematic review study revealed an evident bidirectional 
association between depression and obesity and vice versa especially among females, but considering anxiety and obesity it found a moderate link [10].

A study reported that obesity can cause adjustment depressive symptoms as patients with obesity were encountered to have a 55\% increased risk of developing depression over time. And depression can lead to obesity whereas depressed persons were declared to have a 58\% increased risk of becoming obese [11]. A systematic review study reflected on the improvement of depression, self-esteem, body image, and health-related quality of life especially (vitality) concurrently after engaging in dietary and behavioral weight loss programs [12]. Another study remarked on the high incidence rate of obesity among women with a noticeable relation between (anxiety and depression) and (weight change and obesity) among them [13]. Active weight-loss interventions have showed marked reduction in depressive symptoms in patients with obesity upon undergoing different modalities of weight loss programs like dietary counseling, diet-alone, supervised exercise sessions, pharmacotherapy, lifestyle modification programs with social support provided, and CBT which aimed at enhancing self-acceptance, reducing the perception of stigma, and fostering a sense of mastery and self-control [14].

Regarding management of obesity with psychiatric comorbidities, psycho-education is very important about the risk factors and the importance of early detection and treatment, also liaison psychological and psychopharmacological treatment can facilitate weight loss and improve the clinical and functional outcome [15] therefore there is an emergent call to join patients in stress management techniques such as: diaphragmatic breathing, progressive muscle relaxation, guided visualization and to adopt healthy dietary habits in order to achieve successful weight reduction and to control anxiety and depression [16].

Therefore, our study aimed at elucidating the association of psychiatric morbidities and obesity in females, and hypothesized the reduction of anxiety, depression, perceived stress, and improvement of quality of life, after weight loss than prior.

\section{Methods}

\section{Participants and procedure}

This is an observational longitudinal study with convenient sampling carried out on 41 adult female patients at the obesity clinic at Menoufia University Hospitals, Egypt, from December 2015 till May 2016. There was no case drop out recorded. All participants were selected from female patients seeking weight loss programs for cosmetic purpose only, after explaining the purpose and procedure of the study, and obtaining written informed consent ensuring their confidentiality. Their age ranged from 18 to 55 years old (as young and middle ages were especially selected for their higher ability to follow weight reduction instructions especially exercising and because these two age categories are more subjected to emotional stress due to weight criticism, with BMI 30 $\mathrm{kg} / \mathrm{m}^{2}$ or more). All subjects underwent dietary regimen set by professional nutritionists; based on their basal metabolic caloric requirement; and exercise on an escalating schedule; they were followed in the next visit as regards sticking to the nutritional rehabilitation program. No psychiatric intervention was given to the subjects. Patients having general medical causes of obesity like hypothyroidism, Cushing syndrome, or liver illnesses or taking medications that can cause weight gain like the hormonal contraceptive methods or cortisone were excluded from the sample. Also those with a known history of psychiatric disorder (like depression, binge eating, and bulimia nervosa) or undergoing any kind of psychiatric treatment or receiving psychotropic medications that can increase the body weight were excluded. Each interviewed patient was seen once again on a follow-up session 3 months later to complete the same assessment questionnaires. A 3-month duration between the 2 interviews was specifically chosen upon the standard first follow-up visit time set by nutritionist clinics to assess the anthropometric, dietary, and health effects of the nutritional interventional programs. After using the Central Limit Theorem that justifies the least sample size number to be 30 besides assessing the average number of patients attending the obesity clinic weekly, we estimated the total sample size to be 40 . The study follows the Research Ethics Committee of the Faculty of Medicine, Menoufia University, Egypt.

\section{Measures}

A predesigned sheet on demographic data including age, educational level (basic education: pre-primary, primary, and preparatory level, middle education (general, vocational/technical, and the dual-system vocational levels), and high education (University education level)), marital status and BMI (that is measured before and after weight loss).

Hospital Anxiety and Depression Scale (HADS) [17]. Depressive and anxiety symptoms were assessed by the Arabic translated version of The Hospital Anxiety and Depression Scale. This self-assessment scale covers both anxiety and depression dimensions containing 14 items: 7 items referring to anxiety and 7 to depression, with a cut-off point of 8 for anxiety and 9 for depression. Each item's score ranges from $0-3$ so the person can score between 0 and 21 for either anxiety or depression. All items refer exclusively to the severity of the emotional state only without including the somatic symptoms. Answering the scale takes $2-5 \mathrm{~min}$. 
The Perceived Stress Scale-10 (PSS-10) [18]. We did not use the Arabic translated version. It consists of 10 items that inquire the degree to which respondents appraise their current life situation through the past month being stressful, unpredictable, and uncontrollable by responding on a 5 -point Likert scale $(0=$ never, $1=$ almost never, $2=$ sometimes, $3=$ fairly often, $4=$ very often). Higher scores refer to higher perceived stress. The scale takes 5-10 min to be completed.

Short-Form 36 Health Survey (SF-36). Health-related quality of life (HEQoL) was assessed by applying the Arabic version of the Short-Form 36 Health Survey (SF36) [19]. The scale is designed to measure the quality of life as a reflection of the patient's health status, provided health care services outcome, and to assess disease burden. It is composed of 36 questions that evaluate the following domains: physical functioning (the ability to take care of oneself and to perform routine daily activities); role limitations caused by physical health problems (the impact of physical health in performing activities); bodily pain (level of pain experienced while performing routine daily activities); general health perceptions (how the individual perceives his/her health); vitality (energy and fatigue); social functioning (impact of physical conditions on his/her social life); role limitations caused by emotional problems (the extent to which emotional problems interfere in routine daily activities); and the mental health domain (effect of mood on his/her life). The scores range from 0 (most affected) to 100 (not affected). The scale requires $10 \mathrm{~min}$ to be filled.

\section{Study procedure}

Interview 1: Patients had a primary interview that took around $30 \mathrm{~min}$ where they answered items of the predesigned sheet and the 3 assessment scales and BMI was measured.

Interview 2: Patients were contacted via phone to arrange a meeting with the researcher on their 3 month follow-up visit at the obesity clinic where the predesigned sheet and the same 3 scales were answered and the BMI was measured as well.

\section{Statistical analysis}

All data were recorded in a statistical package on a compatible computer. Results were tabulated and statistically analyzed by the Statistical Package for the Social Sciences (SPSS) version 20 [20]. Wilcoxon signed-rank test was used to compare the patients' results before and after weight loss. Mann Whitney test was used to compare the results of highly educated patients with those with middle education and single to married patients, before and after weight loss. Spearman correlation was used to detect correlations; whether positive or negative; between different variables. Statistically significant findings were determined by a two tailed $P$ value $<0.05$.

\section{Results \\ Demographics data}

The present study included 41 females with age ranging between 19 and 48, with mean age $29.73 \pm 7.7$; considering the marital status, 17 (41.5\%) were single and 24 participants (48.5\%) were married. Regarding the educational level, $21(51.2 \%)$ of the participants completed their high education (University education), while 20 (48.8\%) completed middle education (Technical education). At the start of the study participants' BMI ranged between 29.76 and 56.14, with a mean of $36.3 \pm 6.4$, which decreased 3 months later to a range of 24.69 to 43.37 with a mean of $29.9 \pm 4.7$.

\section{Anxiety and depression scores before and after weight loss}

There was a statistically significant difference in anxiety symptom scores before and after weight loss $(P=$ 0.0001 ) where scores ranging between 2 and 21 decreased from a mean of $12.1 \pm 5.5$ (before weight loss) to a range of 1 to 15 with a mean of $8.1 \pm 2.9$ (after weight loss).

There was also a statistically significant difference in depression scores before and after weight loss $(P=$ $0.0001)$ where scores ranging between 0 and 21 decreased from a mean of $10.2 \pm 5.5$ (before weight loss) to a range of 0 to 15 with a mean of $7 \pm 3.5$ (after weight loss) (Table 1).

Abnormal levels of anxiety and depression symptoms: HADS 11-21 scores were found in 24 (58.5\%) and 19 females $(46.3 \%)$ respectively before weight loss, while after weight loss only 6 females (14.6\%) showed abnormal HADS scores.

\section{Perceived stress scores before and after weight loss}

The study findings reported high score levels in the PSS10 scale with obesity (with a range of 11 to 40 and a mean of $24.62 \pm 6.47$ ) that significantly decreased (to a range of 11 to 31 and a mean of $20.05 \pm 4.09$ ) after the 3 month weight loss trial (Table 1).

\section{Quality of life scores before and after weight loss}

Except for pain, social functioning, and physical functioning, and all other domains scores were less than fifty before the weight-loss trial. After weight loss, all the eight SF-36 Health Survey domain scores increased to reach higher than fifty (Table 2 ).

No correlations were found between BMI and psychiatric morbidities (anxiety symptom, depression symptom, and perceived stress scores). Only an inverse correlation was found between body weight and "role 
Table 1 Anxiety, depression, and perceived stress scores before and after weight loss

\begin{tabular}{lllll}
\hline Variable & Before weight loss & After weight loss & Wilcoxon test & $P$ value \\
\hline HADS anxiety & $12.1 \pm 5.5$ & $8.10 \pm 2.9$ & -4.42 & $0.0001^{*}$ \\
HADS depression & $10.20 \pm 5.5$ & $7 \pm 3.5$ & -4.26 & $0.0001^{*}$ \\
Perceived stress & $24.62 \pm 6.47$ & $20.05 \pm 4.09$ & -4.55 & $0.0001^{*}$ \\
\hline
\end{tabular}

*Significant

limitations caused by emotional problems" QoL domain (rho $-0.345, p<0.027$ ), yet this correlation was not found after weight loss.

\section{Obesity-related psychiatric correlates in relation to educational level}

Regarding education, participants with high education rank showed significantly lower BMI than subjects with middle education level before and after the weight-loss trial.

Also, participants with high education also showed significantly lower perceived stress, anxiety, and depression scores before weight loss when compared with those with middle education, with a statistically significant difference between both groups regarding perceived stress factor $(P=0.005)$ (Table 3$)$. And after weight loss trial, they also showed significantly lower stress, depression scores, and more improvement in the "general health perception" and "role limitations caused by emotional problems" QoL domain scores than participants with middle education, with statistically significant difference between both groups regarding perceived stress factor $(P$ $=0.004)$ (Table 4).

\section{Obesity and its psychiatric correlates in relation to marital status}

No statistically significant differences were found between single and married participants regarding BMI before and after the weight loss trial. Married participants showed higher anxiety and depression scores $(p<0.001)$ and lower scores on physical functioning and vitality domains of the QoL scale before weight loss in comparison to single participants. All these differences between the two groups were not found after the weight-loss trial.

\section{Discussion}

Obesity in relation to depressive and anxiety symptoms Our study findings showed abnormal levels of anxiety and depressive symptoms in $58.5 \%$ and $46.3 \%$ of patients respectively with obesity (before engaging in the weight loss programs). The strong link between anxiety and obesity can be explained by the negative impact of obesity on the patient's self-esteem with the sense of being socially ridiculed [21] especially with poor sociocultural support and awareness about body dissatisfaction and body image, and this can lead to various picture of anxiety-like panic attacks and social phobia. While the evident link between depression and obesity can be explained by the restricted daily routine like low physical activity, relational problems, marital problems, emotional, and physical abuse vulnerability, besides the obesity-related physical complications burden causing frustration and more of chronic stress. Also, symptoms of anxiety are not only reported to increase the appetite but to stimulate craving for high-sugar and high-fat foods as well [22-24]. Likely many studies pointed out the strong association between obesity and anxiety and depressive symptoms [25-29].

In agreement with our results concerning the significant comorbidity of anxiety symptoms and obesity, an Egyptian study screening 93 Arab females at the obesity clinic demonstrated that the severity of anxiety symptoms was positively correlated with the subjects' age, maximum weight, BMI, duration of obesity (in years),

Table 2 Comparison between SF-36 quality of life scores before and after weight loss

\begin{tabular}{|c|c|c|c|c|}
\hline SF-36 domains & Before weight loss & After weight loss & Wilcoxon test & $P$ value \\
\hline Physical functioning & $52.65 \pm 19.8$ & $80.12 \pm 20.7$ & -5.13 & $0.0001^{*}$ \\
\hline Role limitations due to physical problems & $36.1 \pm 44.85$ & $68.6 \pm 42.9$ & -4.08 & $0.0001^{*}$ \\
\hline Bodily pain & $61.95 \pm 86.03$ & $64.63 \pm 18.87$ & -3.77 & $0.0001^{*}$ \\
\hline General health perceptions & $39.42 \pm 9.83$ & $62.69 \pm 3.80$ & -3.71 & $0.0001^{*}$ \\
\hline Vitality & $39.02 \pm 22.03$ & $54.11 \pm 17.12$ & -5.05 & $0.0001^{*}$ \\
\hline Social functioning & $50.35 \pm 22.88$ & $56.8 \pm 22.14$ & -1.95 & 0.05 \\
\hline Role limitations due to emotional problems & $39.84 \pm 47.26$ & $60.97 \pm 46.49$ & -3.08 & $0.002^{*}$ \\
\hline Mental health & $45.34 \pm 18.57$ & $55.41 \pm 13.37$ & -3.84 & $0.0001^{*}$ \\
\hline
\end{tabular}

*Significant 
Table 3 Education level in relation to anxiety, depression, and perceived stress before weight reduction

\begin{tabular}{lllll}
\hline & High education & Middle education & Mann-Whitney & P value \\
\hline Anxiety & $10.45 \pm 4.95$ & $13.75 \pm 5.66$ & -2.047 & 0.041 \\
Depression & $8.35 \pm 5.47$ & $12.05 \pm 5.10$ & -2.413 & 0.016 \\
Perceived stress & $21.85 \pm 5.78$ & $27.50 \pm 5.8$ & -2.918 & $0.004^{*}$ \\
\hline
\end{tabular}

*Significant

and duration since last pregnancy [30]. Another review study revealed high anxiety levels in patients with obesity and higher in those with morbid obesity, which can be explained by the susceptibility of patients with obesity to public and private discrimination, being deprived of many life opportunities, contracting poor socioeconomic status, having fragile social support, facing continuous societal pressure to control their weight problem, frustration after repeated failed attempts of dieting, and resisting preoccupation by eating, plus the fear of having physical complications associated with obesity [31].

And regarding the significant morbidity of depression with obesity, various studies found a close association between obesity and depression [32-37] due to the positive relation between depression and emotional eating [38] as well as the associated poor body image, lack of competence, interpersonal problems, and internalization of weight bias with obesity [32].

Furthermore, a study found that atypical depression is associated with chronic psycho-immuno-neuro-endocrinal dysfunction due to inflammatory, leptin-ghrelin, neuroendocrinal, and gut microbiome systems influenced by chronic image-associated psychological stress and sensitivity to rejection especially in young female patients that can lead to behavioral dysregulation in the form of hyperphagia, lethargy, and hypersomnia [39].

The current study found that anxiety and depression scores decreased after weight reduction and this can be explained by the strong bidirectional relation between anxiety and depression causing emotional eating and obesity, this is supported by the findings of Bulik and colleagues in 2002 [40] who found that compared to obese women without binge eating, obese women with binge eating reported a higher rate of occurrence of psychiatric problems like neuroticism, depression, anxiety disorders (panic disorder, phobia, obsessive-compulsive traits), insomnia, psychomotor agitation or retardation, and suffering from major general medical diseases.
Another study showed that greater improvements in depression were associated with better weight loss outcomes in women in rural parts of states in the USA [41]. In addition, a 5 session aerobic exercise protocol per week during 12 months period and nutritional rehabilitation proved to give better depression level reduction compared to a control group $(P \leq 0.05)$ with the physical activity group showing more improvement than the diet group ( $P=0.001, P=0.006)$ [42]. On the other hand, dietary interventions for weight loss had a significant impact on reducing the magnitude of obesity, depression, and anxiety symptoms [43] because of their antiinflammatory, neuroprotective, and prebiotic properties $[44,45]$.

\section{Obesity in relation to perceived stress}

Our study showed a high perceived stress associated with obesity that was markedly reduced post-weight control, and this explains the effect of obesity on the patient causing chronic stress due to the struggling with poor self-image, lack of self-esteem, continuous criticism, social alienation, leading to more of food craving as a way of coping and stress relief and being more trapped in the obesity loop. And such stress is associated with neuro-endocrinal effects on altering glucose metabolism, insulin sensitivity, cortisol level, and other hormones related to energy homeostasis which can concomitantly affect the dopaminergic reward center activity for increased consumption of highly palatable foods [46].

Agreeing with our results, a study found that $47.1 \%$ of patients with obesity referred to hospital settings had pathological General Health Questionnaire scores [47]. Nevertheless, a positive correlation was found between perceived stress and uncontrolled eating and emotional eating behaviors [48] as well as increased body mass index [48-51].

Table 4 Education level in relation to anxiety, depression, and perceived stress after weight reduction

\begin{tabular}{lllll}
\hline & High education & Middle education & Mann-Whitney & $P$ value \\
\hline Anxiety & $7.3 \pm 2.85$ & $8.9 \pm 2.97$ & -1.708 & 0.08 \\
Depression & $5.65 \pm 3.04$ & $8.35 \pm 3.49$ & -2.543 & 0.011 \\
Perceived stress & $18.35 \pm 3.83$ & $21.84 \pm 3.66$ & -2.788 & $0.005^{*}$ \\
\hline
\end{tabular}




\section{Obesity in relation to quality of life}

The current study findings revealed an inverse correlation between obesity and "role limitations caused by emotional problems" QoL domain with an improvement in the majority of the QoL domains after weight reduction.

Agreeing with our results, a study found that female patients suffering from obesity had an inverse correlation between obesity and both the physical and the mental components of the HRQoL scale, also physical component scores of the HRQoL (physical functioning, role physical, bodily pain, vitality, general health conception) were associated with higher BMI grades, higher educational achievement, and more psychiatric comorbidities [52]. Moreover, a study showed that obesity had an impact on $20.3 \%$ of the general health quality of life of females and $17.8 \%$ of their physical functioning [53].

Also, more of an inverse correlation between obesity and health-related quality of life was demonstrated in other studies [54-56]. Many patients were motivated to seek weight-loss treatment due to their significant difficulties with physical and occupational functioning [57, 58], as weight loss was reported to be typically associated with improvements in psychosocial status and functioning [59].

\section{Educational level in relation to obesity and its psychiatric comorbidities}

Our study revealed that high education is accompanied by lower anxiety, depression, and perceived stress scores before and after weight reduction compared to female patients with middle education level with statistically significant difference regarding perceived stress factor $(P=$ $0.004,0.005$, before and after weight reduction respectively). This can be explained by the notion that reaching high education facilitates better coping with stress, and this is supported by the findings of a study revealing that higher perceived stress was associated with greater intake of energy from fat, high-fat snacks, and fast-food items as well as lower intake of energy from carbohydrates [60]. Similarly, a study reflected that women with university degrees had a $2.1 \mathrm{~kg} / \mathrm{m}^{2}$ lower BMI compared to that of women with lower education levels because of being more preoccupied by body image issues and leading a higher energy expenditure lifestyle [61]. Also, the prevalence of depression was found to be associated with lower educational level [33, 62], lower economic status, and metabolic syndrome than the control group [62].

\section{Conclusion}

Female patients with obesity (especially ones with higher education level) recorded lower anxiety, depression, and perceived stress scores as well as higher quality of life scores after weight reduction than before joining weight loss programs. These findings can help obesity clinic team implement updated systems of screening for psychiatric comorbidities with obesity (especially stress, anxiety, and depression) and monitoring them during weight reduction procedures. In addition, it is necessary to assess the severity of such morbidities in order to determine the most suitable plan of management for each patient like cognitive behavior therapy, interpersonal psychotherapy, improving one's coping and stress management strategies, and using pharmacotherapy if needed.

\section{Strength and limitations}

The study did not highlight the causes of obesity in the patients, and whether they have underlying binge eating disorder or not as it can contribute to and be related to the presence of anxiety, depression, and stress in the patients. Also, the small sample size makes it difficult to give representative findings for all the population.

\section{Abbreviations}

BMI: Body mass index; HADS: Hospital Anxiety and Depression Scale; PSS10: The Perceived Stress Scale-10; SF-36: Short-Form 36 Health Survey; HEQoL: Health-related quality of life; SPSS: Statistical Package for the Social Sciences

\section{Acknowledgements}

We are expressing our cordial gratitude to the appreciated effort and time given by all patients in the study.

\section{Authors' contributions}

A.S.S: offering the research idea and sampling plan, contribution in paper writing, methodology. S.A.S: recruiting and interviewing the patients, applying the questionnaires and sample collection. D.A.M.: contribution in paper writing and revising the references, paper submission. All authors have read and approved the manuscript.

\section{Funding}

This research did not receive any specific grant from funding agencies in the public, commercial, or not-for-profit sectors.

Availability of data and materials

Data will not be shared, as wished by the participants in the study.

\section{Ethics approval and consent to participate}

Subjects were enrolled in the study after explaining the purpose and procedure of the study and obtaining a written informed consent ensuring their confidentiality. The study follows the Research Ethics Committee of the Faculty of Medicine, Menoufia University, Egypt. The reference number of the Committee approval is not available.

\section{Consent for publication}

Not applicable.

\section{Competing interests}

The authors have no competing interests to report.

\section{Author details}

${ }^{1}$ Neuropsychiatry Department, Faculty of Medicine, Menoufia University, Shibin El Kom, Menoufia, Egypt. ${ }^{2}$ Anesthesia, Intensive Care and Pain Management Department, Faculty of Medicine, Menoufia University, Shibin El Kom, Menoufia, Egypt. ${ }^{3}$ Okasha Institute of Psychiatry, Neuropsychiatry Department, Faculty of Medicine, Ain Shams University, Ramsis Street, Abbassia Square, Cairo 11591, Egypt. 
Received: 7 May 2020 Accepted: 21 October 2020 Published online: 06 November 2020

\section{References}

1. World Health Organization (1998) Obesity. Preventing and managing the global epidemic. World Health Organization, Geneva

2. Manyanga T, El-Sayed H, Doku DT, Randall JR (2014) The prevalence of underweight, overweight, obesity and associated risk factors among schoolgoing adolescents in seven African countries. BMC Public Health 14:887

3. Torres SJ, Nowson CA (2007) Relationship between stress, eating behavior, and obesity. Nutrition 23:887-894

4. Dallman MF, Pecoraro NC, la Fleur SE (2005) Chronic stress and comfort foods: self-medication and abdominal obesity. Brain Behav Immun 19:275-280

5. Yau YHC, Potenza MN (2013) Stress and eating behaviors. Minerva Endocrinol 38(3):255-267

6. Stunkard A, Faith MS, Allison KC (2003) Depression and obesity. Biol Psychiatry 54:330-337

7. Al-Qahtani AA, Nahar S, Al-Ahmari SM, AlQahtani KSA (2015) Association between obesity and mental disorders among male students of King Khalid University, Abha, Saudi Arabia. Saudi J Obesity 3:48-54

8. Jorm AF, Korten AE, Christensen H, Jacomb PA, Rodgers B, Parslow RA (2003) Association of obesity with anxiety, depression and emotional wellbeing: a community survey. Aust N Z J Public Health 27(4):434-440

9. Kamel A, Abuhegazy H, Ismaila A, Sherra K, RamadaN M, MekkY A, Al Nabawy A (2016) The prevalence of obesity in a sample of Egyptian psychiatric patients. Egypt J Psychiatr 37(3):157-165

10. Rajan TM, Menon V (2017) Psychiatric disorders and obesity: a review of association studies. J Postgrad Med 63(3):182-190

11. Luppino FS, de Wit LM, Bouvy PF, Stijnen T, Cuijpers P, Penninx BWJH, Zitman FG (2010) Overweight, obesity, and depression. A systematic review and meta-analysis of longitudinal studies. Arch Gen Psychiatry 67(3):220-229

12. Lasikiewicz N, Myrissa K, Hoyland A, Lawton CL (2014) Psychological benefits of weight loss following behavioural and/or dietary weight loss interventions. A systematic research review. Appetite 72:123-137

13. Brumpton B, Langhammer A, Romundstad P, Chen Y, Mai X-M (2013) Behavior and psychology. The associations of anxiety and depression symptoms with weight change and incident obesity: the HUNT study. Int J Obes 37:1268-1274

14. Fabricatore AN, Wadden TA, Higginbotham AJ, Faulconbridge LF, Nguyen AM, Heymsfield SB, Faith MS (2011) Intentional weight loss and changes in symptoms of depression: a systematic review and meta-analysis. Int J Obes (Lond) 35(11):1363-1376

15. Calderone A, Calabro PF, Lippi C, Jaccherl R, Vittli J, Santini F (2017) Psychopathological behaviour and cognition in morbid obesity. Recent Pat Endocr Metab Immune Drug Discov 10(2):112-118

16. Xenaki N, Bacopoulou F, Kokkinos A, Nicolaides NC, Chrousos GP, Darviri C (2018) Impact of a stress management program on weight loss, mental health and lifestyle in adults with obesity: a randomized controlled trial. J Mol Biochem 7(2):78-84

17. Zigmond AS, Snaith RP (1983) The hospital anxiety and depression scale. Acta Psychiat Scand 67(6):361-370

18. Cohen S, Kamarck T, Mermelstein R (1983) A global measure of perceived stress. J Health Soc Behav 24:385-396

19. Ware JE, Snow KK, Kosinski M, Gandek B (1993) SF-36 ${ }^{\circledR}$ health survey manual and interpretation guide. New England Medical Center, The Health Institute, Boston

20. IBM Corp (2011) IBM SPSS statistics for windows, version 20.0. IBM Corp, Armonk

21. van Vuuren $\mathrm{CL}$, Wachter GG, Veenstra R, Rijnhart JJM, van der Wal MF, Chinapaw MJM, Busch V (2019) Associations between overweight and mental health problems among adolescents, and the mediating role of victimization. BMC Public Health 19(1):612

22. Canetti L, Bachar E, Berry EM (2002) Food and emotion. Behav Process 60: $157-164$

23. Nieuwenhuizen AG, Rutters F (2008) The hypothalamic-pituitary-adrenal-axis in the regulation of energy balance. Physiol Behav 94:169-177

24. Yannakoulia M, Panagiotakos DB, Pitsavos C, Tsetsekou E, Fappa E, Papageorgiou C, Stefanadis C (2008) Eating habits in relations to anxiety symptoms among apparently healthy adults. A pattern analysis from the ATTICA study. Appetite 51:519-525
25. Simon GE, Von Korff M, Saunders K, Miglioretti DL, Crane PK, van Belle G, Kessler RC (2006) Association between obesity and psychiatric disorders in the US adult population. Arch Gen Psychiatry 63(7):824-830

26. Petry NM, Barry D, Pietrzak RH, Wagner JA (2008) Overweight and obesity are associated with psychiatric disorders: results from the National Epidemiologic Survey on Alcohol and Related Conditions. Psychosom Med 70(3):288-297

27. Strine TW, Mokdad AH, Dube SR, Balluz LS, Gonzalez O, Berry JT, Manderscheid R, Kroenke K (2008) The association of depression and anxiety with obesity and unhealthy behaviors among community-dwelling US adults. Gen Hosp Psychiatry 30(2):127-137

28. Zhao G, Ford ES, Dhingra S, Li C, Strine TW, Mokdad AH (2009) Depression and anxiety among US adults: associations with body mass index. Int J Obes (Lond) 33(2):257-266

29. Singh G, Jackson C, Dobson A, Mishra GD (2014) Bidirectional association between weight change and depression in mid-aged women: a population-based longitudinal study. Int J Obes 38:591-596

30. Rabie MA, Abo-El-Ezz NF, Salah-El-Din M (2010) Anxiety and social anxiety symptoms among overweight females seeking treatment for obesity. MECP 17(4):13-20

31. Gariepy G, Nitka D, Schmitz N (2010) The association between obesity and anxiety disorders in the population: a systematic review and meta-analysis. IJO 34(3):407-419

32. Sarigiani PA, Olsavsky AL, Camarena PM, Sullivan SM (2020) Obesity and depressive symptoms in college women: analysis of body image experiences and comparison to non-obese women. Int J Adolesc Youth 25(1):765-779

33. Kranjac AW, Nie J, Trevisan M, Freudenheim JL (2017) Depression and body mass index, differences by education: evidence from a population-based study of adult women in the U.S. Buffalo-Niagara region. Obes Res Clin Pract 11(1):63-71

34. Hong SM, Hur YI (2017) Relationship between obesity and depression in Korean adults: Korea National Health and Nutrition Examination Survey 2014. Medicine (Baltimore) 96(52):e9478

35. Mulugeta A, Zhou A, Power C, Hyppönen E (2018) Obesity and depressive symptoms in mid-life: a population-based cohort study. BMC Psychiatry 18(1):297

36. Luo H, Li J, Zhang Q, Cao P, Ren X, Fang A, Liao H, Liu L (2018) Obesity and the onset of depressive symptoms among middle-aged and older adults in China: evidence from the CHARLS. BMC Public Health 18(1):909

37. Chauvet-Gelinier JC, Roussot A, Cottenet J, Brindisi MC, Petit JM, Bonin B, Vergès B, Quantin C (2019) Depression and obesity, data from a national administrative database study: Geographic evidence for an epidemiological overlap. PLoS One 14(1):e0210507

38. Konttinen H, van Strien T, Männistö S, Jousilahti P, Haukkala A (2019) Depression, emotional eating and long-term weight changes: a populationbased prospective study in younger participants, but not in older participants. Int J Behav Nutr Phys Act 16:28

39. Patist CM, Stapelberg NJC, Du Toit EF, Headrick JP (2018) The brainadipocyte-gut network: linking obesity and depression subtypes. Cogn Affect Behav Neurosci 18:1121-1144

40. Bulik CM, Sullivan PF, Kendler KS (2002) Medical and psychiatric morbidity in obese women with and without binge eating. Int J Eat Disord 32(1):72-78

41. Carson TL, Jackson BE, Nolan TS, Williams A, Baskin ML (2017) Lower depression scores associated with greater weight loss among rural black women in a behavioral weight loss program. Transl Behav Med 7(2):320329

42. Irandoost K, Taheri M, Seghatoleslami A (2015) The effects of weight loss by physical activity and diet on depression levels of highly depressed elderly females. Salmand: Iran J Ageing 10(1):48-53

43. Firth J, Marx W, Dash S, Carney R, Teasdale SB, Solmi M, Stubbs B, Schuch FB, Carvalho AF, Jacka F, Sarris J (2019) The effects of dietary improvement on symptoms of depression and anxiety: a meta-analysis of randomized controlled trials [published correction appears in Psychosom Med. 2020 Jun; 82(5):536]. Psychosom Med 81(3):265-280

44. González R, Ballester I, López-Posadas R, Suárez MD, Zarzuelo A, MartínezAugustin O, Sánchez de Medina F (2011) Effects of flavonoids and other polyphenols on inflammation. Crit Rev Food Sci Nutr 51:331-362

45. Chang SC, Cassidy A, Willett WC, Rimm EB, O'Reilly EJ, Okereke OI (2016) Dietary flavonoid intake and risk of incident depression in midlife and older women. Am J Clin Nutr 104:704-714 
46. Chu DT, Minh Nguyet NT, Nga VT, Thai Lien NV, Vo DD, Lien N, Nhu Ngoc VT, Son LH, Le DH, Nga VB, Van Tu P, Van To T, Ha LS, Tao Y, Pham VH (2019) An update on obesity: mental consequences and psychological interventions. Diabetes Metab Syndr: Clin Res Rev 13(1):155-160

47. Vázquez C, Alcaraz F, Balsa JA, Zamarrón I, Arrieta F, Botella Carretero JI (2008) Prevalencia de casos psiquiátricos en pacientes con sobrepeso u obesidad atendidos en consultas externas de un centro hospitalario [Prevalence of psychiatric cases in overweight or obese patients attended in a hospital outpatient clinic]. Med Clin (Barc) 130(2):41-46

48. Richardson AS, Arsenault JE, Cates SC, Muth MK (2015) Perceived stress, unhealthy eating behaviors, and severe obesity in low-income women. Nutr J 14:122

49. Alsultan NFM, Alanazi MD, Boholigah AA, Alsayafi ZA, Alzahrani Y, Boholigah AA, Alnahwi KA, Nasserullah LZ, Nasserullah LZ (2018) The influence of stress on body mass index among female university students. EJHM 73(3): 6359-6366

50. Goswami B (2017) Prevalence of stress and its association with body weight among the medical students of Jorhat Medical College and Hospital, Jorhat. Int J Sci Stud 4(11):1-3

51. Sinha R, Jastreboff AM (2013) Stress as a common risk factor for obesity and addiction. Biol Psychiatry 73(9):827-835

52. Olszanecka-Glinianowicz M, Zygmuntowicz M, Owczarek A, Elibol A, Chudek $J$ (2014) The impact of overweight and obesity on health-related quality of life and blood pressure control in hypertensive patients. J Hypertens 32(2): 397-407

53. Audureau E, Pouchot J, Coste J (2016) Gender-related differential effects of obesity on health-related quality of life via obesity-related comorbidities: a mediation analysis of a French nationwide survey. Circ Cardiovasc Qual Outcomes 9(3):246-256

54. Xu Y, Zhou Z, Li Y, Yang J, Guo X, Gao J, Yan J, Chen G (2015) Exploring the nonlinear relationship between body mass index and health-related quality of life among adults: a cross-sectional study in Shaanxi Province, China. Health Qual Life Outcomes 13:153

55. Fontaine KR, Barofsky I (2001) Obesity and health-related quality of life. Obes Rev 2(3):173-182

56. Jia H, Lubetkin El (2005) The impact of obesity on health-related quality-oflife in the general adult US population. J Public Health (Oxf) 27(2):156-164

57. Fabricatore AN, Wadden TA, Sarwer DB, Faith MS (2005) Health-related quality of life and symptoms of depression in extremely obese persons seeking bariatric surgery. Obes Surg 15(3):304-309

58. Sarwer DB, Lavery M, Spitzer J (2012) A review of the relationships between extreme obesity, quality of life, and sexual function. Obes Surg 22(4):668676

59. Sarwer DB, Polonsky HM (2016) The psychosocial burden of obesity. Endocrinol Metab Clin North Am 45(3):677-688

60. Barrington WE, Beresford SA, McGregor BA, White E (2014) Perceived stress and eating behaviors by sex, obesity status, and stress vulnerability: findings from the vitamins and lifestyle (VITAL) study. J Acad Nutr Diet 114(11):17911799

61. Hermann S, Rohrmann S, Linseisen J, May AM, Kunst A, Besson H, Romaguera D, Travier N, Tormo MJ, Molina E, Dorronsoro M, Barricarte A, Rodríguez L, Crowe FL, Khaw KT, Wareham NJ, van Boeckel PG, Bueno-deMesquita HB, Overvad K, Jakobsen MU, Tjønneland A, Halkjær J, Agnoli C, Mattiello A, Tumino R, Masala G, Vineis P, Naska A, Orfanos P, Trichopoulou A, Kaaks R, Bergmann MM, Steffen A, Van Guelpen B, Johansson I, Borgquist S, Manjer J, Braaten T, Fagherazzi G, Clavel-Chapelon F, Mouw T, Norat T, Riboli E, Rinaldi S, Slimani N, Peeters PH (2011) The association of education with body mass index and waist circumference in the EPIC-PANACEA study. BMC Public Health 11(1):169 BioMed Central

62. Kim B, Park EY (2010) The combined effect of socioeconomic status and metabolic syndrome on depression: the Korean National Health and Nutrition Examination Survey (KNHANES). BMC Public Health 20:617

\section{Publisher's Note}

Springer Nature remains neutral with regard to jurisdictional claims in published maps and institutional affiliations.

\section{Submit your manuscript to a SpringerOpen ${ }^{\circ}$ journal and benefit from:}

- Convenient online submission

- Rigorous peer review

- Open access: articles freely available online

- High visibility within the field

- Retaining the copyright to your article

Submit your next manuscript at $\boldsymbol{\nabla}$ springeropen.com 